\title{
CONCOMITANT CONTACT ALLERGY TO FORMALDEHYDE AND METHACRYLIC MONOMERS IN STUDENTS OF DENTAL MEDICINE AND DENTAL PATIENTS
}

\section{MAYA LYAPINA ${ }^{1}$, MARIA DENCHEVA ${ }^{2}$, ASSYA KRASTEVA ${ }^{2}$, MARIANA TZEKOVA ${ }^{2}$, and ANGELINA KISSELOVA-YANEVA ${ }^{2}$}

\author{
${ }^{1}$ Medical University, Sofia, Bulgaria \\ Medical Faculty, Department of Hygiene, Medical Ecology and Nutrition \\ ${ }^{2}$ Medical University, Sofia, Bulgaria \\ Faculty of Dental Medicine, Department of Oral and Image Diagnostic
}

\begin{abstract}
Objectives: A multitude of acrylic monomers is used in dentistry. Formaldehyde is a ubiquitous chemical agent, which is an ingredient of some dental materials and may be released from methacrylate-based composites. The purpose of the study is to evaluate the incidence and the risk of cross-sensitization to some methacrylic monomers (methylmethacrylate - MMA, triethyleneglycol dimethacrylate - TEGDMA, ethyleneglycol dimethacrylate - EGDMA, 2,2-bis-[4-(2-hydroxy-3-methacrylo-xypropoxy)phenyl]-propane - Bis-GMA, 2-hydroxy-ethyl methacrylate 2-HEMA, and tetrahydrofurfuryl methacrylate) and formaldehyde in students of dentistry, dental professionals and dental patients. Material and Methods: A total of 139 participants were included in the study, i.e., occupationally exposed dental professionals, students of the $3 \mathrm{rd}$, 4th and 6th year of dental medicine, and occupationally unexposed dental patients. They were patch-tested with methacrylic monomers and formaldehyde. The results were subjected to statistical analysis $(\mathrm{p}<0.05)$. Results: From the allergic to formaldehyde students of the $3 \mathrm{rd}$ and 4 th year of dental medicine, $46.2 \%$ were also sensitized to MMA. Among the group of patients, the incidence of cross-sensitization to formaldehyde and methacrylic monomers was as follows: to TEGDMA - 20.6\%, to ethyleneglycol dimethacrylate $-20.7 \%$, to 2-HEMA $-20.7 \%$ and to tetrahydrofurfuryl methacrylate $-24.1 \%$. Contact allergy to MMA was diagnosed among $22.7 \%$, and to TEGDMA - among $27.1 \%$ of the students of the 3rd and 4th year of dental medicine. In the group of occupationally unexposed dental patients the prevalence of contact allergy to ethyleneglycol dimethacrylate was $20.7 \%$, to Bis-GMA $-27.6 \%$, to 2-HEMA $-44.9 \%$ and to tetrahydrofurfuryl methacrylate $-38.0 \%$. Conclusions: The students of the 3rd and 4th year of dental medicine could be outlined as a group at risk of sensitization to MMA and TEGDMA and of cross-sensitization to MMA and formaldehyde. Probably, due to the ubiquitous occurrence of formaldehyde and the wide use of composite resins and bonding agents containing TEGDMA, ethyleneglycol dimethacrylate, 2-HEMA and tetrahydrofurfuryl methacrylate in dentistry, the group of dental patients could be at risk of cross-sensitization to formaldehyde and some methacrylic monomers.
\end{abstract}

Key words:

Allergic contact dermatitis, Formaldehyde, Methacrylic monomers, Co-reactivity, Dental students, Dental patients

The study was granted by the Medical University, Sofia - Project No. 1-C/2012 "Pilot investigation of the onset of occupational sensitization to formaldehyde in students of dental medicine and in dental professionals, exposed during the practical education.” Manager of project: Angelina Kisselova-Yaneva, D.D.S., PhD, DSc. Received: August 30, 2013. Accepted: July 18, 2014.

Corresponding author: M. Lyapina, Department of Hygiene, Medical Ecology and Nutrition, Medical Faculty, Medical University, 15 Blvd "Acad. Ivan Evstr. Geshov," 1431 Sofia, Bulgaria (e-mail: saly_grigory@abv.bg). 


\section{INTRODUCTION}

A multitude of acrylic monomers is used in dentistry. Acrylic resin dentures contain methylmethacrylate (MMA) as residual monomer [1]. Commercial dental restorative materials (e.g., bonding materials, composite resins and glass ionomers) were also shown to contain methacrylates. The most frequently occurring methacrylates in bonding materials are 2-hydroxy-ethyl methacrylate (2-HEMA) and 2,2-bis-[4-(2-hydroxy-3-methacrylo-xypropoxy)phenyl]-propane (Bis-GMA). Bis-GMA and triethyleneglycol dimethacrylate (TEGDMA) are the most frequently occurring methacrylates in composite resins. The main methacrylate of the glass ionomers is 2-HEMA or trimethylolpropane trimethacrylate (TMPTMA) [2].

Methacrylate-containing materials are almost always mixtures of methacrylates and acrylates, which contain inhibitors, activators and other reactive compounds. The examples include: reaction initiators (e.g., benzoyl peroxide), reaction activators (e.g., tertiary amines), cross-linking agents (e.g., formaldehyde), reaction inhibitors (e.g., hydroquinone) and resin carriers [3]. All of these additives are known contact sensitizers and several are known or suspected respiratory sensitizers and/or respiratory irritants [4,5].

Formaldehyde is formed as an oxidation product of the residual methylmethacrylate monomer and may be released from methacrylate-based dental materials, such as composites and denture bases [6-9]. It is responsible for allergic inflammation in acrylic denture wearers and thus, it seems necessary to study its leaching from denture-base materials [10].

Formaldehyde is a ubiquitous chemical agent, a part of our general outdoor environment, as well as of our indoor working and residential environment. It is believed that whole civilized population is exposed to formaldehyde [11]. Formaldehyde is still used as an ingredient of some dental materials - root-canal-filling materials, formocresol, etc. [12]. Cohen et al. (1998) and Koch (1999) evaluated the release of formaldehyde from some endodontic materials - root canal filling sealers. As a result they have demonstrated that all materials showed the highest release of formaldehyde in the case of freshly mixed samples [13,14].

Both MMA and formaldehyde have been often associated with local allergic reactions in the patients' oral mucosa as a result of contact with prosthetic and orthodontic devices [15]. Other reported adverse reactions include: contact dermatitis and occupationally-induced respiratory hypersensitivity due to volatilization in dental professionals $[16,17]$. Such reactions could be also observed in dental students exposed to methacrylic monomers and formaldehyde during their practical education.

In their everyday practice dental professionals are occupationally exposed to a variety of dental materials, containing formaldehyde and methacrylic monomers. Students of dental medicine are exposed to such materials during their practical education. Due to the common exposure to such materials in dental practice we suggested a possible cross-sensitization to methacrilyc monomers and to formaldehyde. No studies have been found in the available literature concerning this topic.

\section{OBJECTIVES}

The purpose of the present study was to evaluate the incidence and the risk of cross-sensitization to some methacrylic monomers and to formaldehyde in students of dental medicine, dental professionals (dentists, nurses and attendants) and patients.

\section{MATERIAL AND METHODS}

A total of 139 participants, divided into 4 groups, were included in the study: occupationally exposed to (meth)acrylates and acrylic monomers dental professionals, students of the $3 \mathrm{rd}$ and 4 th year of dental medicine, students of the 6th year of dental medicine, and patients without occupational exposure to acrylates, serving as a control 
Table 1. General characteristics of the studied groups

\begin{tabular}{lcccc}
\hline & \multicolumn{4}{c}{ Respondents } \\
\cline { 2 - 5 } \multicolumn{1}{c}{ Group } & $\begin{array}{c}\text { age } \\
\text { (years) } \\
(\mathrm{M} \pm \mathrm{SD})\end{array}$ & $\begin{array}{c}\text { total } \\
{[\mathrm{n}(\%)]}\end{array}$ & $\begin{array}{c}\text { male } \\
{[\mathrm{n}(\%)]}\end{array}$ & $\begin{array}{c}\text { female } \\
{[\mathrm{n}(\%)]}\end{array}$ \\
\hline Patients without occupational exposure & $47.34 \pm 18.21$ & $29(20.9)$ & $72(4.10)$ & $22(75.9)$ \\
Students of the 3rd and 4th year of dental medicine & $22.05 \pm 1.29$ & $44(31.7)$ & $17(38.6)$ & $27(61.4)$ \\
Students of the 6th year of dental medicine & $26.39 \pm 6.79$ & $28(20.1)$ & $11(39.3)$ & $17(60.7)$ \\
Occupationally exposed dental professionals & $52.32 \pm 13.41$ & $38(27.3)$ & $8(21.1)$ & $30(78.9)$ \\
Total & - & $139(100.0)$ & $43(30.9)$ & $96(69.1)$ \\
\hline
\end{tabular}

group. General characteristics of the studied subjects are presented in Table 1.

The study was approved by the Medical Ethics Board at Medical University - Sofia. All the participants were informed about the purpose of the study and gave their written informed consent before its commencement.

\section{Questionnaire survey}

Interviews and a detailed, questionnaire-based survey with an emphasis on family history, suspected or known allergies to standard set of household or occupational allergens, history of frequent, recurrent respiratory system infections and manifestation of subjective symptoms, as well as a review of medical documentation were performed.

\section{Skin patch testing}

Skin patch testing with methyl methacrylate (MMA), triethyleneglycol dimethacrylate (TEGDMA), ethyleneglycol dimethacrylate (EGDMA), 2,2-bis[4-(2-hydroxy-3-methacryloxypropoxy)phenyl]-propane (Bis-GMA), 2-hydroxyethyl methacrylate (2-HEMA), tetrahidrofurfuril metacrylate $(0.2 \%$ pet, Chemotechnique Diagnostics) and formaldehyde (0.1\%/aq, Art. No. F002A, Chemotechnique Diagnostics) was performed according to the Jadassohn \& Bloch classical methods for diagnosis of contact allergy, by placing the allergens in IQ-Ultra hypoallergenic patches of Chemotechnique Diagnostics (IQ Chambers ${ }^{\circledR}$,
Vellinge, Sweden). Lack of anti-allergic medication constituted a mandatory condition before placing the patches and during the testing. Patches with allergens were applied on the back of the tested individuals, reading of the test was performed on day 2, several hours after removing the patches, with control revision on day 3 .

Interpretation of reaction sites was based on the method recommended by the International Contact Dermatitis Research Group (ICDRG). Interpretation key based on recommendations by the ICDRG was applied (Table 2).

Table 2. Interpretation key of skin patch test results based on International Contact Dermatitis Research Group

\begin{tabular}{|c|c|}
\hline Symbol & Meaning \\
\hline$(-)$ & negative reaction \\
\hline$?$ & doubtful reaction \\
\hline+ & weak positive reaction (non-vesicular) \\
\hline++ & strong positive reaction (oedematous or vesicular) \\
\hline+++ & extreme positive reaction (ulcerative or bullous) \\
\hline IR & irritant reaction \\
\hline
\end{tabular}

\section{Statistical methods}

The statistics were calculated with SPSS 19.0. The following statistics available for cross-tabulation were used: $\mathrm{Chi}^{2}$ test, Fisher Exact Test for statistical significance, testing of the ratio of 2 probabilistic odds ratio (OR). Values of $p<0.05$ were accepted as statistically significant. 


\section{RESULTS}

Distribution by gender was not uniform, with predominance of women in all the investigated groups, but without statistical significance $\left(\mathrm{Chi}^{2}=4.5, \mathrm{p}=0.212\right)$.

Logically, the mean age in the groups of occupationally exposed dental professionals and the occupationally unexposed patients was significantly higher compared to the groups of students. With respect to the duration of exposure to methacrylates and formaldehyde in dental practice, the data is predictable:

- 0 years for occupationally unexposed patients,

- 1-2 years for the students of the 3 rd and 4 th year of dental medicine,

- 4 years for the students of the 6 th year of dental medicine and a number (1-50) of years for the occupationally exposed dental personnel.

Individuals without a history of allergic pathology prevailed in all the studied groups, with no reliable differences in the overall distribution. The number of subjects without a history of atopy in the group of dental professionals was significantly lower compared with the groups of students of the 3rd and 4th year of dental medicine ( $p=0.044)$ and of the 6th year of the studies $(\mathrm{p}=0.047)$.
Data concerning the incidence of cross-sensitization to methyl methacrylate (MMA) and formaldehyde in the investigated groups are summarized in Table 3.

No statistically significant differences were found in the overall distribution, as well as in the between-groups analysis $(\mathrm{p}=0.106)$. However, attention should be paid to the fact that about $1 / 3$ of the individuals allergic to formaldehyde were also sensitized to MMA (in the case of the group of students of the 3rd and 4th year of dental medicine the incidence was $46.2 \%$ ). Interestingly, the between-groups analysis revealed a significantly higher incidence of sensitization to MMA only in the group of students of the $3 \mathrm{rd}$ and 4 th year of dental medicine compared with the group of dental professionals $\left(\mathrm{Chi}^{2}=5.764, \mathrm{p}=0.016\right)$.

Summary of the data concerning the incidence of cross-sensitization to triethyleneglycol dimethacrylate (TEGDMA) and formaldehyde is presented in Table 4.

With exception of the group of dental professionals, about half of the individuals sensitized to formaldehyde were also allergic to TEGDMA (triethyleneglycol dimethacrylate). The highest incidence of sensitization to TEGDMA occurred in the group of students of the 3rd and 4th year of dental medicine, with statistical significance compared

Table 3. Distribution of positive skin patch test reactions to methyl methacrylate (MMA) and formaldehyde (F) among the studied groups

\begin{tabular}{|c|c|c|c|c|c|c|c|c|c|c|}
\hline \multirow[t]{2}{*}{ Target group } & \multicolumn{2}{|c|}{$\begin{array}{l}\text { Negative reaction } \\
\text { to MMA vs. } \\
\text { negative } \\
\text { reaction to F }\end{array}$} & \multicolumn{2}{|c|}{$\begin{array}{l}\text { Positive reaction } \\
\text { to MMA vs. } \\
\text { negative } \\
\text { reaction to } F\end{array}$} & \multicolumn{2}{|c|}{$\begin{array}{l}\text { Negative reactions } \\
\text { to MMA vs. } \\
\text { positive } \\
\text { reaction to F }\end{array}$} & \multicolumn{2}{|c|}{$\begin{array}{l}\text { Positive reaction } \\
\text { to MMA vs. } \\
\text { positive } \\
\text { reaction to } F\end{array}$} & \multicolumn{2}{|c|}{ Total } \\
\hline & $\mathrm{n}$ & $(\%)$ & $\mathrm{n}$ & $(\%)$ & $\mathrm{n}$ & $(\%)$ & $\mathrm{n}$ & $(\%)$ & $\mathrm{n}$ & $(\%)$ \\
\hline Occupationally unexposed patients & 13 & $(44.8)$ & 5 & $(17.3)$ & 7 & (24.1) & 4 & $(13.8)$ & 29 & $(100)$ \\
\hline $\begin{array}{l}\text { Students of the } 3 \text { rd and } 4 \text { th year } \\
\text { of dental medicine }\end{array}$ & 22 & $(50.0)$ & 10 & (22.7) & 7 & $(15.9)$ & 5 & $(11.4)$ & 44 & $(100)$ \\
\hline $\begin{array}{l}\text { Students of the 6th year of dental } \\
\text { medicine }\end{array}$ & 13 & $(46.4)$ & 3 & $(10.7)$ & 9 & $(32.1)$ & 3 & $(10.7)$ & 28 & $(100)$ \\
\hline Dental professionals & 27 & (71.1) & 3 & $(7.9)$ & 5 & $(13.1)$ & 3 & $(7.9)$ & 38 & $(100)$ \\
\hline Total & 75 & $(54.0)$ & 21 & $(15.1)$ & 28 & $(20.1)$ & 15 & $(10.8)$ & 139 & $(100)$ \\
\hline
\end{tabular}


Table 4. Distribution of positive skin patch test reactions to triethyleneglycol dimethacrylate (TEGDMA) and formaldehyde (F) among the studied groups

\begin{tabular}{|c|c|c|c|c|c|c|c|c|c|c|}
\hline \multirow[t]{2}{*}{ Target group } & \multicolumn{2}{|c|}{$\begin{array}{c}\text { Negative reaction } \\
\text { to TEGDMA vs. } \\
\text { negative } \\
\text { reaction to } \mathrm{F}\end{array}$} & \multicolumn{2}{|c|}{$\begin{array}{l}\text { Positive reaction } \\
\text { to TEGDMA vs. } \\
\text { negative } \\
\text { reaction to F }\end{array}$} & \multicolumn{2}{|c|}{$\begin{array}{c}\text { Negative reaction } \\
\text { to TEGDMA vs. } \\
\text { positive } \\
\text { reaction to } \mathrm{F}\end{array}$} & \multicolumn{2}{|c|}{$\begin{array}{c}\text { Positive reaction } \\
\text { to TEGDMA vs. } \\
\text { positive } \\
\text { reaction to } \mathrm{F}\end{array}$} & \multicolumn{2}{|c|}{ Total } \\
\hline & $\mathrm{n}$ & $(\%)$ & $\mathrm{n}$ & $(\%)$ & $\mathrm{n}$ & $(\%)$ & $\mathrm{n}$ & $(\%)$ & $\mathrm{n}$ & $(\%)$ \\
\hline $\begin{array}{l}\text { Occupationally unexposed } \\
\text { patients }\end{array}$ & 13 & $(44.8)$ & 5 & $(17.3)$ & 5 & $(17.3)$ & 6 & $(20.6)$ & 29 & $(100)$ \\
\hline $\begin{array}{l}\text { Students of the } 3 \text { rd and } 4 \text { th year } \\
\text { of dental medicine }\end{array}$ & 20 & $(45.6)$ & 12 & $(27.1)$ & 6 & $(13.6)$ & 6 & $(13.6)$ & 44 & $(100)$ \\
\hline $\begin{array}{l}\text { Students of the 6th year of dental } \\
\text { medicine }\end{array}$ & 13 & $(46.4)$ & 3 & (10.7) & 7 & $(25.0)$ & 5 & $(17.9)$ & 28 & $(100)$ \\
\hline Dental professionals & 25 & $(65.8)$ & 5 & $(13.2)$ & 6 & $(15.7)$ & 2 & $(5.3)$ & 38 & $(100)$ \\
\hline Total & 71 & $(51.1)$ & 25 & $(17.9)$ & 24 & $(17.3)$ & 19 & (13.7) & 139 & $(100)$ \\
\hline
\end{tabular}

Table 5. Distribution of positive skin patch test reactions to ethyleneglycol dimethacrylate (EGDMA) and formaldehyde (F) among the studied groups

\begin{tabular}{|c|c|c|c|c|c|c|c|c|c|c|}
\hline \multirow[t]{2}{*}{ Target group } & \multicolumn{2}{|c|}{$\begin{array}{l}\text { Negative reaction } \\
\text { to EGDMA vs. } \\
\text { negative } \\
\text { reaction to F }\end{array}$} & \multicolumn{2}{|c|}{$\begin{array}{l}\text { Positive reaction } \\
\text { to EGDMA vs. } \\
\text { negative } \\
\text { reaction to F }\end{array}$} & \multicolumn{2}{|c|}{$\begin{array}{l}\text { Negative reaction } \\
\text { to EGDMA vs. } \\
\text { positive } \\
\text { reaction to } \mathrm{F}\end{array}$} & \multicolumn{2}{|c|}{$\begin{array}{l}\text { Positive reaction } \\
\text { to EGDMA vs. } \\
\text { positive } \\
\text { reaction to F }\end{array}$} & \multicolumn{2}{|c|}{ Total } \\
\hline & $\mathrm{n}$ & $(\%)$ & $\mathrm{n}$ & $(\%)$ & $\mathrm{n}$ & $(\%)$ & $\mathrm{n}$ & $(\%)$ & $\mathrm{n}$ & $(\%)$ \\
\hline $\begin{array}{l}\text { Occupationally unexposed } \\
\text { patients }\end{array}$ & 12 & $(41.4)$ & 6 & $(20.7)$ & 5 & $(17.2)$ & 6 & $(20.7)$ & 29 & $(100)$ \\
\hline $\begin{array}{l}\text { Students of the } 3 \text { rd and } 4 \text { th year } \\
\text { of dental medicine }\end{array}$ & 27 & $(61.4)$ & 5 & (11.4) & 6 & $(13.6)$ & 6 & $(13.6)$ & 44 & $(100)$ \\
\hline $\begin{array}{l}\text { Students of the 6th year of dental } \\
\text { medicine }\end{array}$ & 12 & $(42.9)$ & 4 & $(14.3)$ & 7 & $(25.0)$ & 5 & $(17.8)$ & 28 & $(100)$ \\
\hline Dental professionals & 27 & $(71.1)$ & 3 & (7.9) & 5 & (13.1) & 3 & $(7.9)$ & 38 & (100) \\
\hline Total & 78 & $(56.1)$ & 18 & $(12.9)$ & 23 & $(16.6)$ & 20 & $(14.4)$ & 139 & $(100)$ \\
\hline
\end{tabular}

to the group of dental professionals $\left(\mathrm{Chi}^{2}=4.886\right.$, $\mathrm{p}=0.027$ ). Statistical analysis of overall distribution revealed an increased incidence and OR of cross-sensitization to formaldehyde and to TEGDMA $\left(\mathrm{Chi}^{2}=4.519\right.$, $\mathrm{p}=0.034, \mathrm{OR}=2.248,95 \% \mathrm{CI}: 1.057-4.784)$, without intra-groups relevant differences.

The results of skin patch testing to formaldehyde and ethyleneglycol dimethacrylate are presented in Table 5.
Statistical analysis revealed an increased incidence and OR of cross-sensitization to formaldehyde and to ethyleneglycol dimethacrylate in the overall distribution $\left(\mathrm{Chi}^{2}=11.522, \mathrm{p}=0.001, \mathrm{OR}=3.768,95 \% \mathrm{CI}: 1.713-8.29\right)$. More than half of the individuals sensitized to formaldehyde from the patients group and the group of students of the 3rd and 4th year of dental medicine were also allergic to EGDMA, with statistical significance for the latter 
Table 6. Distribution of positive skin patch test reactions to 2,2-bis-[4-(2-hydroxy-3-methacrylo-xypropoxy)phenyl]-propane (Bis-GMA) and formaldehyde $(\mathrm{F})$ among the studied groups

\begin{tabular}{|c|c|c|c|c|c|c|c|c|c|c|}
\hline \multirow[t]{2}{*}{ Target groups } & \multicolumn{2}{|c|}{$\begin{array}{l}\text { Negative reaction } \\
\text { to Bis-GMA vs. } \\
\text { negative } \\
\text { reaction to F }\end{array}$} & \multicolumn{2}{|c|}{$\begin{array}{c}\text { Positive reaction } \\
\text { to Bis-GMA vs. } \\
\text { negative } \\
\text { reaction to F }\end{array}$} & \multicolumn{2}{|c|}{$\begin{array}{l}\text { Negative reaction } \\
\text { to Bis-GMA vs. } \\
\text { positive reaction } \\
\text { to F }\end{array}$} & \multicolumn{2}{|c|}{$\begin{array}{c}\text { Positive reaction } \\
\text { to Bis-GMA vs. } \\
\text { positive } \\
\text { reaction to } \mathrm{F}\end{array}$} & \multicolumn{2}{|c|}{ Total } \\
\hline & $\mathrm{n}$ & $(\%)$ & $\mathrm{n}$ & $(\%)$ & $\mathrm{n}$ & $(\%)$ & $\mathrm{n}$ & $(\%)$ & $\mathrm{n}$ & $(\%)$ \\
\hline $\begin{array}{l}\text { Occupationally unexposed } \\
\text { patients }\end{array}$ & 8 & $(27.0)$ & 10 & $(34.5)$ & 8 & $(27.6)$ & 3 & $(10.3)$ & 29 & (100) \\
\hline $\begin{array}{l}\text { Students of the } 3 \text { rd and } 4 \text { th year of } \\
\text { dental medicine }\end{array}$ & 26 & $(59.1)$ & 5 & (11.4) & 7 & $(15.9)$ & 6 & $(13.6)$ & 44 & $(100)$ \\
\hline $\begin{array}{l}\text { Students of the 6th year of dental } \\
\text { medicine }\end{array}$ & 10 & $(35.7)$ & 6 & (21.4) & 7 & $(25.0)$ & 5 & $(17.8)$ & 28 & $(100)$ \\
\hline Dental professionsals & 27 & $(75.0)$ & 3 & $(8.3)$ & 4 & $(11.1)$ & 2 & $(5.6)$ & 36 & $(100)$ \\
\hline Total & 71 & $(51.8)$ & 25 & $(18.2)$ & 26 & (18.9) & 16 & (11.7) & 137 & $(100)$ \\
\hline
\end{tabular}

group $\left(\mathrm{Chi}^{2}=6.906 ; \mathrm{p}=0.009\right)$. The rate of sensitization to ethyleneglycol dimethacrylate in the group of patients was significantly higher in comparison with the one in the group of dental professionals $\left(\mathrm{Chi}^{2}=4.258, \mathrm{p}=0.039\right)$.

The data on the results from patch testing to formaldehyde and Bis-GMA are presented below (Table 6).

More than $1 / 3$ of the individuals allergic to formaldehyde were also sensitized to Bis-GMA in the groups of dental students and dental professionals, the prevalence again being the highest in the group of students of the 3rd and 4th year of dental medicine (46.2\%). No statistically significant differences were found in the overall distribution $(p=0.154)$. Sensitization rate to Bis-GMA was significantly higher only in the patients group $\left(\mathrm{Chi}^{2}=5.19\right.$, $p=0.023$ ) and in the group of students of the 6th year of dental medicine $\left(\mathrm{Chi}^{2}=4.392, \mathrm{p}=0.036\right)$ compared with the group of dental professionals.

The prevalence of sensitization to 2-hydroxyethyl methacrylate (2-HEMA) and formaldehyde is presented in Table 7. The results were similar to the ones reported above $-54.5 \%$ of the subjects allergic to formaldehyde from the group of occupationally unexposed patients were also sensitized to 2-HEMA. Sensitization rate to 2-HEMA was relevantly higher in the patients group $\left(\mathrm{Chi}^{2}=4.001, \mathrm{p}=0.045\right)$ compared to the group of dental professionals. No statistically significant differences were found in the overall distribution ( $p=0.307)$.

Data concerning the prevalence of cross-sensitization to tetrahydrofurfuryl methacrylate and formaldehyde are intriguing (Table 8).

Sensitization to tetrahydrofurfuryl methacrylate was observed among $63.6 \%$ of the occupationally unexposed patients allergic to formaldehyde and among $53.8 \%$ of the students of the 3rd and 4th year of dental medicine allergic to formaldehyde, with statistical significance for the latter group $\left(\mathrm{Chi}^{2}=5.543, \mathrm{p}=0.019\right)$. Sensitization rate to tetrahydrofurfuryl methacrylate was found to be significantly higher in the group of patients compared with the dental professionals $\left(\mathrm{Chi}^{2}=9.583, \mathrm{p}=0.002\right)$.

In conclusion, statistical analysis of the overall distribution revealed an increased incidence and OR of cross-sensitization to tetrahydrofurfuryl methacrylate and formaldehyde $\left(\mathrm{Chi}^{2}=9.273, \mathrm{p}=0.002, \mathrm{OR}=3.247,95 \% \mathrm{CI}: 1.496-7.048\right)$. The prevalence of positive skin patch tests to formaldehyde in the studied groups was analyzed statistically. Significantly increased sensitization rates were observed in the group of students of the 6th year of dental medicine compared with the dental professionals $\left(\mathrm{Chi}^{2}=4.696, \mathrm{p}=0.030\right)$. 
Table 7. Distribution of positive skin patch test reactions to 2-hydroxy-ethyl methacrylate (2-HEMA) and formaldehyde (F) among the studied groups

\begin{tabular}{|c|c|c|c|c|c|c|c|c|c|c|}
\hline \multirow[t]{2}{*}{ Target group } & \multicolumn{2}{|c|}{$\begin{array}{l}\text { Negative reaction } \\
\text { to } 2 \text {-HEMA vs. } \\
\text { negative } \\
\text { reaction to F }\end{array}$} & \multicolumn{2}{|c|}{$\begin{array}{l}\text { Positive reaction } \\
\text { to } 2 \text {-HEMA vs. } \\
\text { negative } \\
\text { reaction to F }\end{array}$} & \multicolumn{2}{|c|}{$\begin{array}{l}\text { Negative reaction } \\
\text { to } 2 \text {-HEMA vs. } \\
\text { positive } \\
\text { reaction to } \mathrm{F}\end{array}$} & \multicolumn{2}{|c|}{$\begin{array}{c}\text { Positive reaction } \\
\text { to } 2 \text {-HEMA vs. } \\
\text { positive } \\
\text { reaction to } F\end{array}$} & \multicolumn{2}{|c|}{ Total } \\
\hline & $\mathrm{n}$ & $(\%)$ & $\mathrm{n}$ & $(\%)$ & $\mathrm{n}$ & $(\%)$ & $\mathrm{n}$ & $(\%)$ & $\mathrm{n}$ & $(\%)$ \\
\hline $\begin{array}{l}\text { Occupationally unexposed } \\
\text { patients }\end{array}$ & 13 & $(44.9)$ & 5 & $(7.2)$ & 5 & $(17.2)$ & 6 & $(20.7)$ & 29 & $(100)$ \\
\hline $\begin{array}{l}\text { Students of the 3rd and 4th year } \\
\text { of dental medicine }\end{array}$ & 23 & $(52.3)$ & 8 & $(18.2)$ & 8 & $(18.2)$ & 5 & (11.3) & 44 & $(100)$ \\
\hline $\begin{array}{l}\text { Students of the 6th year of dental } \\
\text { medicine }\end{array}$ & 10 & $(35.7)$ & 6 & $(21.4)$ & 10 & $(35.7)$ & 2 & $(7.2)$ & 28 & $(100)$ \\
\hline Dental professionals & 24 & $(66.7)$ & 6 & $(16.7)$ & 4 & $(11.1)$ & 2 & $(5.6)$ & 36 & (100) \\
\hline Total & 70 & $(51.2)$ & 25 & $(18.2)$ & 27 & $(19.7)$ & 15 & $(10.9)$ & 137 & (100) \\
\hline
\end{tabular}

Table 8. Distribution of positive skin patch test reactions to tetrahydrofurfuryl methacrylate (THFMA) and formaldehyde (F) among the studied groups

\begin{tabular}{|c|c|c|c|c|c|c|c|c|c|c|}
\hline \multirow[t]{2}{*}{ Target group } & \multicolumn{2}{|c|}{$\begin{array}{c}\text { Negative reaction } \\
\text { to THFMA vs. } \\
\text { negative } \\
\text { reaction to F }\end{array}$} & \multicolumn{2}{|c|}{$\begin{array}{c}\text { Positive reaction } \\
\text { to THFMA vs. } \\
\text { negative } \\
\text { reaction to } F\end{array}$} & \multicolumn{2}{|c|}{$\begin{array}{c}\text { Negative reaction } \\
\text { to THFMA vs. } \\
\text { positive } \\
\text { reaction to } \mathrm{F}\end{array}$} & \multicolumn{2}{|c|}{$\begin{array}{l}\text { Positive reaction } \\
\text { to THFMA vs. } \\
\text { positive } \\
\text { reaction to F }\end{array}$} & \multicolumn{2}{|c|}{ Total } \\
\hline & $\mathrm{n}$ & $(\%)$ & $\mathrm{n}$ & $(\%)$ & $\mathrm{n}$ & $(\%)$ & $\mathrm{n}$ & $(\%)$ & $\mathrm{n}$ & $(\%)$ \\
\hline $\begin{array}{l}\text { Occupationally unexposed } \\
\text { patients }\end{array}$ & 11 & $(38.0)$ & 7 & $(24.1)$ & 4 & $(13.8)$ & 7 & $(24.1)$ & 29 & $(100)$ \\
\hline $\begin{array}{l}\text { Students of the } 3 \text { rd and } 4 \text { th year } \\
\text { of dental medicine }\end{array}$ & 26 & $(59.1)$ & 6 & (13.6) & 5 & $(11.4)$ & 7 & $(15.9)$ & 44 & $(100)$ \\
\hline $\begin{array}{l}\text { Students of the 6th year of dental } \\
\text { medicine }\end{array}$ & 11 & $(39.3)$ & 5 & $(17.9)$ & 8 & $(28.5)$ & 4 & $(14.3)$ & 28 & $(100)$ \\
\hline Dental professionals & 27 & $(70.0)$ & 3 & $(8.3)$ & 4 & $(11.1)$ & 2 & $(5.6)$ & 36 & $(100)$ \\
\hline Total & 75 & $(54.8)$ & 21 & $(15.3)$ & 21 & $(15.3)$ & 20 & $(14.6)$ & 137 & $(100)$ \\
\hline
\end{tabular}

\section{DISCUSSION}

In the context of immunotoxicology (the study of adverse health effects that may result from interaction of xenobiotics with the immune system), allergic contact dermatitis can be regarded as being the most frequent manifestation of immunotoxicity in humans. It is a common occupational and environmental issue and hundreds of chemicals were shown to cause skin sensitization. Contact allergy is the disease-free state that a skin sensitizer can induce, while allergic contact dermatitis is the disease elicited in an individual with contact allergy [18].

Resin-based dental materials are not inert in the oral environment, and may release numerous components, including monomers and formaldehyde. There are concerns regarding potential toxicity and sensitizing properties of the components that may leach out in the oral cavity [19]. 
Both occupational and non-occupational contact with acrylate and methacrylate (acrylic) monomers have been reported to cause skin symptoms and induce allergies [20]. Information about molecular structure and main uses of the substances tested in the present study is presented below (Figures 1-7).

Methyl methacrylate as a small molecular acrylate can permeate thin protective disposable gloves. Since the 1950s, numerous case reports have documented allergic contact dermatitis to MMA. Dental personnel is at risk when handling acrylic monomers manually while at work. Several studies have indicated that the prevalence of skin symptoms and incidence of sensitization to (meth)acrylates

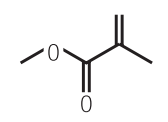

Methyl methacrylate (MMA) - commonly used in orthodontic baseplates and dentures.

Fig. 1. Molecular structure and main uses of MMA

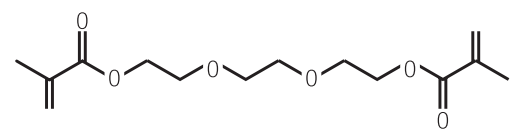

Triethyleneglycol dimethacrylate (TEGDMA) - common monomer in composites, fissure sealants, bonding agents.

Fig. 2. Molecular structure and main uses of TEGDMA

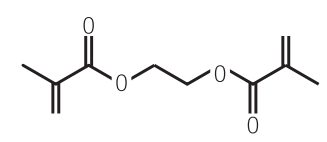

Ethyleneglycol dimethacrylate (EGDMA) - common monomer in composites and bonding agents.

Fig. 3. Molecular structure and main uses of EGDMA

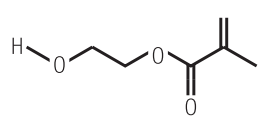

2-Hydroxy-etyl-metacrylate (2-HEMA) - common in dentin-bonding materials and light cured glass-ionomers, cements, used as a raw material to be polymerized in paint, adhesive, coating.

Fig. 4. Molecular structure and main uses of 2-HEMA

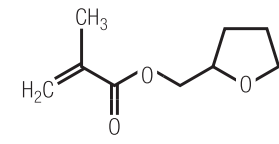

Tetrahydrofurfuryl methacrylate (THFMA) - common in crowns and bridges; used in the formulation of ultraviolet light-curable adhesives, coatings, paints, and printing inks; found in artificial nails.

Fig. 5. Molecular structure and main uses of THFMA<smiles>C=C(C)C(=O)OCC(=O)COc1ccc(C(C)(C)c2ccc(OCC(=O)COC(=O)C(=C)C)cc2)cc1</smiles>

2,2-bis-[4-(2-hydroxy-3-methacrylo-xypropoxy)phenyl]-propane (BisGMA) - common monomer in composite fillings and fissure sealants.

Fig. 6. Molecular structure and main uses of Bis-GMA<smiles>[1H][13C]([3H])=O</smiles>

Formaldehyde - "waste product" from polymerization, ingredient of some dental materials.

Fig. 7. Molecular structure and main uses of formaldehyde

among dental professionals is high [21-26], as well as it is high in the patients undergoing dental treatment and exposed to resin-based materials [27]. Acrylic monomers cross-react, therefore, sensitized individuals are often multiallergic and, accordingly, should not be exposed to any of the compounds [28].

The most intensive exposure of dental students to methacrylates starts during the second year of their education. According to the data collected in the interviews, at that time they were uninformed and unaware of the fact that they should protect themselves by using gloves at work. This is a possible explanation of the high prevalence of contact sensitization to MMA (and some other methacrylic monomers) in the group of students of the $3 \mathrm{rd}$ and 4 th year of dental medicine compared to the dental professionals. The rate of allergic predisposition was higher in the group of students of the 3rd and 4th year compared to the group of dental professionals, but its possible role 
could not be speculated due to the fact, that such was observed in the group of students of the 6th year as well. The probability of release of TEGDMA from composite resins is high, and the risk of allergies and cytotoxicity has been recognized [29-31].

The increased incidence and OR of cross-sensitization to formaldehyde and TEGDMA among the total population studied by us is most probably due to the ubiquitous occurrence of formaldehyde and the wide use of TEGDMAcontaining dental materials. The group of students of the 3rd and 4th year of dental medicine seems to be more susceptible to TEGDMA sensitization compared with the group of dental professionals.

Occupational exposure doesn't seem to be the main factor for the onset of sensitization to ethyleneglycol dimethacrylate since we established a higher sensitization rate in the group of patients when compared to the dental professionals. Concerning the incidence and OR of cross-sensitization to formaldehyde and Bis-GMA, no statistical significance in the overall distribution was revealed. Our findings confirm the statement of the U.S. Department of Health and Human Services (HHS) cited by the American Dental Association (ADA), saying: "Dental sealant exposure to bisphenol A occurs primarily with use of dental sealants containing bisphenol A dimethacrylate. This exposure is considered an acute and infrequent event with little relevance to estimating general population exposures" [32]. The only known consumer exposure to 2-HEMA in its monomeric form is through its use in dentistry [33,34]. The relevantly higher sensitization rate to 2-HEMA in the patients group compared with the group of dental professionals suggests a leading role of consumer (dental patient's) exposure in the sensitization onset.

The statement about a leading role of consumer's exposure seems to be valid in the case of sensitization rates to tetrahydrofurfuryl methacrylate. Interestingly, during the interviews, numerous female students self-related the positive skin patch test results with the use of nail products.

\section{CONCLUSIONS}

The students of the 3rd and 4th year of dental medicine were intensively exposed to MMA and other (meth)acrylic monomers for 1-2 years in the course of their education, often without being adequately informed about safety at work and proper personal protection. They could be outlined as a susceptible group at risk of sensitization to MMA and TEGDMA, as well as of cross-sensitization to MMA and formaldehyde.

On the other hand, most probably due to the ubiquitous occurrence of formaldehyde and the wide use of composite resins and bonding agents containing TEGDMA, ethyleneglycol dimethacrylate, 2-HEMA and tetrahydrofurfuryl methacrylate in dentistry, the group of dental patients seems to be at risk of cross-sensitization to formaldehyde and the listed methacrylic monomers.

Our results suggest a leading role of consumer exposure in the onset of contact sensitization to ethyleneglycol dimethacrylate (EGDMA), Bis-GMA, 2-HEMA and tetrahydrofurfuryl methacrylate.

More efficient risk management and training programs about health and safety at work with proper personal protective devices among the exposed to formaldehyde and methacrylates dental students and dental professionals, as well as limitations of general exposures could be recommended.

\section{REFERENCES}

1. Keyf FA, Keyf AI. Harmful effects of methylmethacrylate and formaldehyde from acrylic resin denture base materials. Saudi Dent J. 1998;10(1):25-8.

2. Henriks-Eckerman ML, Suuronen K, Jolanki R, Alanko K. Methacrylates in dental restorative materials. Contact Dermatitis. 2004;50(4):233-7.

3. Borak J, Fields C, Andrews LS, Pemberton MA. Methyl methacrylate and respiratory sensitization: A critical review. Crit Rev Toxicol. 2011;41(3):230-68, http://dx.doi.org/10. 3109/10408444.2010.532768. 
4. Kanerva L, Henriks-Eckerman ML, Estlander T, Jolanki R, Tarvainen K. Occupational allergic contact dermatitis and composition of acrylates in dentin bonding systems. J Eur Acad Dermatol Venerol. 1994;3:157-68, http://dx.doi.org/ 10.1111/j.1468-3083.1994.tb00091.x.

5. Enoch SJ, Roberts DW, Cronin MTD. Electrophilic reaction chemistry of low molecular weight respiratory sensitizers. Chem Res Toxicol. 2009;22:1447-53, http://dx.doi.org/10. 1021/tx9001463.

6. Ruyter IF. Release of formaldehyde from denture base polymers. Acta Odontal Scand. 1980;38(1):17-27.

7. Tsuchiya H, Hoshino Y, Kato H, Takagi N. Flow injection analysis of formaldehyde leached from denture-base acrylic resins. J Dent. 1993;21:240-3, http://dx.doi.org/ 10.1016/0300-5712(93)90136-E.

8. Oysaed H, Ruyter IE, Sjøvik Kleven IJ. Release of formaldehyde from dental composites. J Dent Res. 1988;67(10):1289-94, http://dx.doi.org/10.1177/002203458 80670100901.

9. Kopperud HM, Kleven IS, Wellendorf H. Identification and quantification of leachable substances from polymer-based orthodontic base-plate materials. Eur J Orthod. 2011;33:26-31, http://dx.doi.org/10.1093/ejo/cjq020.

10. Mikai M, Fujii H. Quantitative analysis of allergenic ingredients in eluate extracted from used denture base resin. J Oral Rehabil. 2006;33(3):216-20, http://dx.doi.org/ 10.1111/j.1365-2842.2005.01561.x.

11. Hazardous Substances Data Bank. National Library of Medicine [cited 2013 Aug 1]. Available from: http://toxnet. nlm.nih.gov/cgi-bin/sis/htmlgen?HSDB.

12. Hauman CHJ, Love RM. Biocompatibility of dental materials used in contemporary endodontic therapy: A review. Part 2, Root-canal-filling materials. Int Endod J. 2003;36:147-60, http://dx.doi.org/10.1046/j.1365-2591. 2003.00637.x.

13. Cohen BI, Pagnillo MK, Musikant BL, Dentsch AS. Evaluation of the release of formaldehyde for three endodontic filling materials. Oral Health. 1998;88:37-9.
14. Koch MJ. Formaldehyde release from root-canal sealers: Influence of method. Int Endod J. 1999;32:10-6, http://dx. doi.org/10.1046/j.1365-2591.1999.00173.x.

15. Chaves CA, Machado AL, Vergani CE, de Souza RF, Giampaolo ET. Cytotoxicity of denture base and hard chairside reline materials: A systematic review. J Prosthet Dent. 2012;107:114-27, http://dx.doi.org/10.1016/ S0022-3913(12)60037-7.

16. Gautam R, Singh RD, Sharma VP, Siddhartha R, Chand P, Kumar R. Biocompatibility of polymethylmethacrylate resins used in dentistry. J Biomed Mater Res B Appl Biomater. 2012;100B:1444-50, http://dx.doi.org/10.1002/ jbm.b.32673.

17. Reichl FX, Walther UI, Durner J, Kehe K, Hickel R, Kunzelmann KH, et al. Cytotoxicity of dental composite components and mercury compounds in lung cells. Dent Mater. 2001;17:95-101， http://dx.doi.org/10.1016/S01095641(00)00029-4.

18. Dietert RR, Luebke RW, editors. Immunotoxicity, immune dysfunction, and chronic disease. New York: Springer; 2011, http://dx.doi.org/10.1007/978-1-61779812-2.

19. van Landuyt KL, Nawrot T, Geebelen B, de Munck J, Snauwaert J, Yoshihara K, et al. How much do resin-based dental materials release? A meta-analytical approach. Dental Materials. 2011;27(8):723-47, http://dx.doi.org/10.1016/j.dental. 2011.05.001.

20. Sasseville D. Acrylates in contact dermatitis. Dermatitis. 2012;23(1):6-16, http://dx.doi.org/10.1097/DER.0b013e3182 $3 \mathrm{~d} 1 \mathrm{~b} 81$.

21. Aalto-Korte K, Alanko K, Kuuliala O, Jolanki R. Methacrylate and acrylate allergy in dental personnel. Contact Dermatitis. 2007;57(5):324-30, http://dx.doi.org/10.1111/j.16000536.2007.01237.x.

22. Alanko K, Susitaival P, Jolanki R, Kanerva L. Occupational skin diseases among dental nurses. Contact Dermatitis. 2004;50(2):77-82, http://dx.doi.org/10.1111/j.0105-1873. 2004.00304.x. 
23. Goon AT, Isaksson M, Zimerson E, Goh CL, Bruze M. Contact allergy to (meth)acrylates in the dental series in southern Sweden: Simultaneous positive patch test reaction patterns and possible screening allergens. Contact Dermatitis. 2006;55(4):219-26, http://dx.doi.org/10.1111/j.1600-0536. 2006.00922.x.

24. Jaakkola MS, Leino T, Tammilehto L, Ylöstalo P, Kuosma E, Alanko K. Respiratory effects of exposure to methacrylates among dental assistants. Allergy. 2007;62(6): 648-54, http://dx.doi.org/10.1111/j.1398-9995.2007.01379.x.

25. Prasad Hunasehally RY, Hughes TM, Stone NM. Atypical pattern of (meth)acrylate allergic contact dermatitis in dental professionals. Br Dent J. 2012;213(5):223-4, http://dx.doi.org/10.1038/sj.bdj.2012.776.

26. Kieć-Świerczyńska M, Kręcisz B. Allergic contact dermatitis in a dental nurse induced by methacrylates. Int J Occup Med Environ Health. 2003;16(1):73-4.

27. Tillberg A, Stenberg B, Berglund A. Reactions to resinbased dental materials in patients-type, time to onset, duration, and consequence of the reaction. Contact Dermatitis. 2009;61(6):313-9, http://dx.doi.org/10.1111/j.1600-0536. 2009.01590.x.

28. Kanerva L. Cross-reactions of multifunctional methacrylates and acrylates. Acta Odontol Scand. 2001;59(5):320-9, http://dx.doi.org/10.1080/000163501750541200.
29. Johansen JD, Frosch PJ, Lepoittevin JP. In: Johansen JD, Frosch PJ, Lepoittevin JP, editors. Contact dermatitis. 5th ed. Berlin: Springer; 2011. p. 773, http://dx.doi.org/10. 1007/978-3-642-03827-3.

30. Polydorou O, König A, Hellwig E, Kümmerer K. Longterm release of monomers from modern dentalcomposite materials. Eur J Oral Sci. 2009;117:68-75, http://dx.doi.org/ 10.1111/j.1600-0722.2008.00594.x.

31. Seiss M, Langer C, Hickel R, Reichl FX. Quantitative determination of TEGDMA, BHT, and DMABEE in eluates from polymerized resin-based dental restorative materials by use of GC/MS. Arch Toxicol. 2009;83(12):1109-15, http://dx.doi.org/10.1007/s00204-009-0470-7.

32. American Dental Association. ADA Positions and statements: Bisphenol A and dental materials [cited 2008 Nov 20]. Available from: http://www.west-end-dental.com/ images/ADABisphenolArticle.pdf.

33. Organization for Economic Co-operation and Development Screening Information Datasets (OECD SIDS). 2-Hydroxyethyl methacrylate [cited 2013 Aug 1]. Available from: http://www.inchem.org/documents/sids/sids/868779.pdf.

34. Ruyter IE. Physical and chemical aspects related to substances released from polymeric materials in aqueous environment. Adv Dent Res. 1995;9(4):344-7, http://dx.doi.org/ 10.1177/08959374950090040101.

This work is available in Open Access model and licensed under a Creative Commons Attribution-NonCommercial 3.0 Poland License - http://creativecommons.org/ licenses/by-nc/3.0/pl/deed.en. 